\title{
ASSOCIATION OF DIABETES MELLITUS WITH STROKE: A HOSPITAL-BASED CASE-CONTROL STUDY
}

\author{
Manoj Kumar1, Kashif Shahnawaz ${ }^{2}$ \\ ${ }^{1}$ Associate Professor, Department of Community Medicine, TMMC \& RC, Moradabad, Uttar Pradesh. \\ ${ }^{2}$ Associate Professor, Department of Community Medicine, LBKMC \& Hospital, Saharsa, Bihar.
}

\begin{abstract}
Stroke is a major cause of mortality and morbidity worldwide. Globally, stroke is the second leading cause of death above the age of 60 years and the fifth leading cause of death in people aged 15-59 years old. In addition to specific complications of diabetes mellitus like nephropathy, retinopathy, etc., some other non-specific complications, notably coronary artery disease and stroke are also increasing in frequency in diabetic patients.
\end{abstract}

\section{MATERIALS AND METHODS}

This was a case-control study conducted from Feb-2016 to Apr-2016 (3 months). Study was done among stroke patients aged 20 years and above hospitalized in TMMC and RC, Moradabad, UP, Age and gender matched control subjects were selected among neurologically healthy people who were admitted for other ailments in this hospital. Sample size was 312 people containing 156 cases and 156 controls. Statistical analysis was done using Med Calc Version 12.7.5.0 software. Chi-square test was used as test of significance and $\mathrm{p}$ value less than 0.05 was considered as significant.

\section{OBSERVATION}

Male:Female ratio among the cases and control was 1.51:1. Mean age of cases and controls were $51.30 \pm 11.13$ and $51.93 \pm 14.60$. Out of 156 cases, 77 (49.36\%) were suffering from Diabetes mellitus, while only 46 (29.48\%) controls were having diabetes mellitus. $P$ value was 0.0003 , which is highly significant.

\section{CONCLUSION}

In the present hospital-based case-control study, diabetes mellitus was found to be a significant risk factor in patients with stroke. Risk factor assessment is an important step towards better understanding of pathogenesis, prevention and control of stroke.

\section{RECOMMENDATIONS}

Physicians caring for patients at risk for stroke should be vigilant for diabetes as well as other concurrent stroke risk factors like hypertension, dyslipidaemia, heart diseases, etc., that tend to cluster with diabetes. Lifestyle modification and non-pharmacological as well as pharmacological interventions for the modifiable risk factors should form an integral aspect of patient care. The prevalence of Type 2 diabetes mellitus is increasing globally, particularly in developing countries. Previously, diabetes mellitus Type 2 was disease of middle aged and elderly, but recently it is affecting younger age group including adolescents especially in the high risk population.

\section{KEYWORDS}

Diabetes Mellitus, Stroke, Case-Control Study.

HOW TO CITE THIS ARTICLE: Kumar M, Shahnawaz K. Association of diabetes mellitus with stroke: a hospital-based case-control study. J. Evolution Med. Dent. Sci. 2016;5(55):3733-3736, DOI: 10.14260/jemds/2016/856

\section{INTRODUCTION}

Stroke is a major cause of mortality and morbidity worldwide and commonly occurs amongst elderly. It is a preventable disease. WHO defines stroke as "Neurological deficit of cerebrovascular cause that persists beyond 24 hours or is interrupted by death within 24 hours. As a result, the affected area of brain is unable to function, leading to inability to move one or more limbs on one side of body, numbness, altered smell, taste, hearing, vision (Total or partial). ${ }^{1}$

Stroke is the second leading cause of disability, after dementia. Disability may include loss of vision and/or speech, paralysis and confusion.

Financial or Other, Competing Interest: None.

Submission 26-05-2016, Peer Review 29-06-2016,

Acceptance 04-07-2016, Published 08-07-2016.

Corresponding Author:

Dr. Kashif Shahnawaz,

Manhar Road, Chhoti Quazipura,

Dist-Darbhanga

Bihar-846004.

E-mail: kashif.shahnawaz98@gmail.com

DOI: $10.14260 /$ jemds $/ 2016 / 856$
In the developing world, however, the incidence of stroke is increasing. In India, prevalence rate of stroke is 1.54 with a death rate of 0.6 per 1000 population. ${ }^{2}$ Incidence of stroke ranges from 182-342 per 100,000 populations in Asia. ${ }^{3}$ There are many risk factors, which influence stroke risk. Most important ones are coronary heart disease, hypertension, diabetes mellitus, smoking and obesity. The risk factors for stroke vary internationally. Its risk factor profile may differ in different population groups. Our present study deals with the association of diabetes with stroke.

The prevalence of diabetes is rapidly rising all over the globe to an alarming rate, particularly in developing nations. It is considered as the epidemic of the $21^{\text {st }}$ century. ${ }^{4}$ According to World Health Organization Report 2005, around 171 million people were affected with diabetes worldwide in year 2000 and worldwide increase is expected to 366 million by the year 2030.5 According to $5^{\text {th }}$ edition of IDF Diabetes Atlas, India is second to China in world for the number of people suffering from diabetes.

Number of people with diabetes in India is estimated around 61.3 million in 2011 and this number is expected to 
rise to 101.2 million by 2030 , unless urgent preventive steps are taken. ${ }^{6}$ Over the past 30 years, the status of diabetes has changed from being considered as mild disorder of elderly to one of the major cause of morbidity and mortality affecting youth and middle aged people. ${ }^{7}$ The maximum burden of society of diabetes is particularly contributed by Type 2 diabetes mellitus. ${ }^{8}$ In addition to specific complications of diabetes mellitus like nephropathy, retinopathy, etc. some other non-specific complications, notably coronary artery disease and stroke are also increasing in frequency in diabetic patients. It is clearly an important risk factor for stroke, especially in those under 65 years of age. ${ }^{9}$ This is mainly due to atherosclerotic vascular disease, the prevalence of which has increased worldwide. ${ }^{10}$

The objective of our present study is to know an association of diabetes mellitus with stroke. The study was well needed as no study has been conducted on stroke, especially in Moradabad district of Uttar Pradesh.

\section{MATERIALS AND METHODS}

The present study was carried out in the Department of Medicine, in collaboration with the Department of Community Medicine, Teerthankar Mahaveer Medical College and Research Centre (TMMC and RC), Moradabad (U.P.), a tertiary care centre to study an association of diabetes mellitus with stroke. Duration of the study was from Feb-2016 to Apr-2016 (3 months). This study was approved by Ethical Committee of TMMC and RC, Moradabad. All the in-patients diagnosed with stroke, controls and their attendants at TMMC and RC, Moradabad, during study period were explained the purpose of study and were invited to participate. Ethical aspects were explained and informed consent was obtained before enrolling them in study.

This was a retrospective, case-control study, in which stroke patients aged 20 years and above hospitalized in TMMC and RC, Moradabad, were taken for study. Age and gender matched control subjects were selected among neurologically healthy people who were admitted for other ailments in this hospital. The control subjects had no prior strokes or any neurological problem/deficit. A total of 358 study subjects (179 cases and 179 controls) were included in the study of which 23 cases could not participate and were drop-outs. To maintain case-control ratio (1:1), 23 controls were excluded from the study. The final sample size was 312 people, containing 156 cases and 156 controls.

Cases were defined as per the definition of WHO, which defines stroke as "Neurological deficit of cerebrovascular cause that persists beyond 24 hours or is interrupted by death within 24 hours. As a result, the affected area of brain is unable to function, leading to inability to move one or more limbs on one side of the body, numbness, altered smell, taste, hearing, vision (Total or partial). ${ }^{1}$ All patients of either sex aged 20 years and above who has stroke verified by CT scan of brain admitted in Medicine Ward of TMMC and RC, Moradabad, were included in this study. The patients who were excluded from this study were those having subarachnoid haemorrhage, transient ischaemic attack, syncopal attack, presumptive diagnosis of stroke with equivocal neurological deficits but no lesion on CT scan brain, neurological deficits secondary to epilepsy or head injury or an infective, metastatic aetiology, pre-existing severe physical or cognitive disability and trigeminal neuralgia.
Study participants were interviewed using a structured interview schedule. Patient's spouse or members of the family were interviewed to cross check the data obtained at their family setting. Help and co-ordination were solicited from the attendants of the patients to complete the schedule as and when needed. Chi-square test was used as test of significance and $\mathrm{p}$ value less than 0.05 was considered as significant. Multivariate analysis was also carried out. The data was analysed using Med Calc Version 12.7.5.0 software.

\section{OBSERVATIONS}

\begin{tabular}{|c|c|c|c|c|}
\hline $\begin{array}{c}\text { Age } \\
\text { Group } \\
\text { (In Yrs.) }\end{array}$ & Cases & Male & Female & Male \\
$(\mathrm{n}=\mathbf{9 4 )}$ & $(\mathrm{n}=\mathbf{6 2})$ & $\begin{array}{c}\text { Female } \\
(\mathrm{n}=\mathbf{9 4})\end{array}$ \\
\hline $\mathbf{n}=\mathbf{6 2})$
\end{tabular}

In cases, $60.26 \%(n=94)$ were males and $39.74 \%(n=62)$ are females. In Controls, $60.26 \%(\mathrm{n}=94)$ were males and $39.74 \%(n=62)$ were females. Male:Female ratio among the cases and control was 1.51:1. Mean age of cases and controls were $51.30 \pm 11.13$ and $51.93 \pm 14.60$.

\begin{tabular}{|c|c|c|c|}
\hline $\begin{array}{l}\text { Diabetes } \\
\text { Mellitus }\end{array}$ & Cases & Controls & p value \\
\hline Present & $\begin{array}{c}77 \\
(49.36 \%)\end{array}$ & $46(29.48 \%)$ & $\begin{array}{c}P= \\
0.0003\end{array}$ \\
\hline Absent & $\begin{array}{c}79 \\
(50.64 \%)\end{array}$ & $\begin{array}{c}110 \\
(70.52 \%)\end{array}$ & \\
\hline Total & $\begin{array}{c}156 \\
(100 \%)\end{array}$ & $\begin{array}{c}156 \\
(100 \%)\end{array}$ & \\
\hline \multicolumn{4}{|c|}{$\begin{array}{c}\text { Table 2: Showing Diabetes Mellitus } \\
\text { among Cases and Controls }\end{array}$} \\
\hline
\end{tabular}

$\mathrm{n}=312 ; \mathrm{OR}=2.33 ;(\mathrm{CI}=1.46-3.71) ; \mathrm{x}^{2}=12.85 ; \mathrm{p}=0.0003 ; \mathrm{df}=1$

Out of 156 cases, 77 (49.36\%) were suffering from Diabetes Mellitus, while only 46 (29.48\%) controls were having diabetes mellitus. $\mathrm{P}$ value was 0.0003 , which is significant.

\section{DISCUSSION}

This study shows that most patients were above 60 years of age and a male preponderance was observed in stroke. Male:Female ratio among the cases and control was 1.51:1. Mean age of cases and controls were $51.30 \pm 11.13$ and $51.93 \pm 14.60$. Studies performed on ischaemic stroke among the 15-45 years' age group from India also reported a male preponderance.11 Similar findings have been reported from Denmark in cases of thromboembolic stroke. ${ }^{12}$ Consistent with the findings of other studies, our present study showed that diabetes mellitus have strong correlation and association with stroke. Guzowski K et al $^{13}$ compared risk factors in 300 patients with brain stroke and 120 patients with neurosis or sciatic pains. 
It was found that diabetes mellitus $(\mathrm{p}=0.01)$ were significantly more frequent in cases of brain stroke. Kannel W $\mathrm{B}$ et $\mathrm{al}^{14}$ examined prospectively, in the Framingham Cohort, the relation of diabetes and impaired glucose tolerance to each of the cardiovascular sequelae, taking into account age, sex and associated cardiovascular risk factors. The incidence of cardiovascular disease, stroke as well as the levels of cardiovascular risk factors was found to be higher in diabetic men and women. Boden-Albala B et $\mathrm{al}^{15}$ observed that more than 47 million individuals in the United States meet the criteria for the metabolic syndrome. The metabolic syndrome was associated with increased risk of stroke (HR=1.5; 95\% CI, 1.1 to 2.2 ) and vascular events (HR=1.6; 95\% CI, 1.3-2.0) after adjustment for socio-demographic and risk factors. Hamidon $\mathrm{B} \mathrm{B}$ et al ${ }^{16}$ reported that diabetes mellitus is a strong risk factor for stroke. One hundred and sixty-three patients with acute ischaemic stroke were enrolled in this study. Type 2 diabetes mellitus was found to be significantly associated with stroke. George et al ${ }^{17}$, using the Nationwide Inpatient Sample (NIS) database, reported an overall increase in hospitalization rates for ischaemic stroke between 1995-96 and 2007-08 for 5-14, 15-34 and 35-44 age groups and a concomitant increase in prevalence rate of diabetes. In some studies, it has been shown that diabetes is an important risk-factor associated with poor post-stroke outcomes and disability. ${ }^{18-20}$

\section{CONCLUSION}

Our present study is a step towards determination of risk factors of stroke. To conclude, in the present hospital-based case-control study, diabetes mellitus was found to be a significant risk factor in patients with stroke. The future burden of stroke is likely to increase in the developing countries because of fast changing lifestyles and increase in diabetes incidence. Risk factor assessment is an important step towards better understanding of pathogenesis, prevention and control of stroke.

\section{RECOMMENDATIONS}

There should be a proper health education and increase in awareness about the primordial prevention of risk factors, which leads to increase in stroke morbidity and mortality. Physicians caring for patients at risk for stroke should be vigilant for diabetes as well as other concurrent stroke risk factors like hypertension, dyslipidaemia, heart diseases, etc., that tend to cluster with diabetes. People should be motivated and encouraged to undergo regular physical exercises and to avoid sedentary life-styles. Life style modification and nonpharmacological as well as pharmacological interventions for the modifiable risk factors should form an integral aspect of patient care.

\section{Limitation of the Study}

There are some limitations in this study. Analysis and interpretation were difficult, because all the patients did not undergo all the required investigations. Being a tertiary care centre, the referred patient's profiles may not be representative, creating a bias. Because of paucity of information, this study gives an idea to undertake more detailed studies with bigger sample sizes to explore the associations and risk factors.

\section{Strength of the Study}

This study was well needed here, as no study has been conducted on stroke in relation with diabetes mellitus, especially in Moradabad. Data regarding prevalence of stroke and its risk factors in U.P. is very scanty. Hence, our present study is a step towards determination of risk factors of stroke.

\section{REFERENCES}

1. World Health Organization. Steps Stroke Manual. Available from www.who.int/chp/steps/stroke. Accessed 23rd October 2009.

2. Park K. Ischaemic heart disease. In: Park's textbook of Preventive and social medicine. 20 2 th ed. Premnagar. Banarasidas Bhanot 314-29.

3. Johnston SC, Mendis S, Mathers CD. Global variation in stroke burden and mortality estimates from monitoring, surveillance and modelling. Lancet Neurol 2009;8(4):345-54.

4. Cheng YJ, Imperatore G, Geiss LS, et al. Secular changes in the age-specific prevalence of diabetes among US adults: 1988-2010. Diabetes Care 2013;36(9):2690-6.

5. Sandhu HS, Koley S, Sandhu KS. Study of correlation between lipid profile and waist-hip ratio in diabetes mellitus. Anthropologist 2008;10(3):215-8.

6. International diabetes federation. IDF $5^{\text {th }}$ Diabetes atlas. Belgium. Indian diabetes federation, 2011.

7. Chandramohan P, Mohan V. High prevalence of diabetes and metabolic syndrome among policemen. JAPI 2008;56:837-8.

8. Osei K. Global epidemic of type 2 diabetes: implications for developing countries. Ethn dis 2003;13(2Suppl): S102-6.

9. Kissela BM, Khoury JC, Alwell K, et al. Age at stroke: temporal trends in stroke incidence in a large, biracial population. Neurology 2012;79(17):1781-7.

10. Gill TM, Allore HG, Halford TR, et al. Hospitalization, restricted activity, and development of disability among older persons. JAMA 2004;292(17):2115-24.

11. Nayak SD, Nair $M$, Radhakrishnan $K$, et al. Ischaemic stroke in the young adult: clinical features, risk factors and outcome. Natl Med J India 1997;10(3):107-12.

12. Lidegard 0 , Soe $M$, Anderson NM. Cerebral thromboembolism among young women and men from Denmark 1997-1982. Stroke 1986;17:670-5.

13. Guzowski K, Hulanicka K, Piechocki DW. Stroke - the role of hyperlipoproteinemia lipid metabolism and various arteriosclerosis risk factors in a control group. Neurol Neurochir Pol 1981;15(4):453-57.

14. Kannel WB, Mc Gee DL. Diabetes and glucose tolerance as risk factors for cardiovascular disease: the Framingham study. Diabetes Care 1979;2(2):120-6.

15. Boden-Albala B, Sacco RL, Lee HS, et al. Metabolic syndrome and ischaemic stroke risk: northern Manhattan study. Stroke 2008;39(1):30-5.

16. Hamidon BB, Raymond AA. The impact of diabetes mellitus on in-hospital stroke mortality. J Postgrad Med 2003;49(4):307-9.

17. George MG, Tong X, Kuklina EV, et al. Trends in stroke hospitalizations and associated risk factors among children and young adults, 1995-2008. Ann Neurol 2011;70(5):713-21. 
18. Jia $Q$, Zhao X, Wang C, et al. Diabetes and poor outcomes within six months after acute ischaemic stroke: the China national stroke registry. Stroke 2011;42(10):2758-62.

19. Callahan A, Amarenco P, Goldstein LB, et al. Risk of stroke and cardiovascular events after ischaemic stroke or transient ischaemic attack in patients with type-2 diabetes or metabolic syndrome: secondary analysis of the stroke prevention by aggressive reduction in cholesterol levels (sparcl) trial. Arch Neurol 2011;68(10):1245-51.
20. Putaela J, Liebkind R, Gordin D, et al. Diabetes mellitus and ischaemic stroke in the young: clinical features and longterm prognosis. Neurology 2011;76(21):1831-7. 